\title{
The Research Progress of Endogenous Formaldehyde in Aquatic Products
}

\author{
Xuan Zhang*, Yunhua Hui, Youqiong Cai, Dongmei Huang \\ East China Sea Fishery Research Institute, Chinese Academy of Fishery Sciences, Shanghai 200090, China \\ Email: "zhangxuan0430@163.com
}

Received 12 September 2015; accepted 15 October 2015; published 22 October 2015

\begin{abstract}
Endogenous formaldehyde in aquatic products is a hot research topic, as it is an urgent problem to be solved. This paper summarized the advance in background concentration, generation mechanism and detection methods of endogenous formaldehyde in aquatic products, and the work in the future was prospected.
\end{abstract}

Keywords

Endogenous Formaldehyde, Aquatic Products, Research Progress

\section{Introduction}

Recently, people are paying more attention to formaldehyde (FA) in aquatic products. FA as a mutagenic and carcinogenic volatile toxic aldehyde [1], even less dose of FA can cause pain, vomiting, lethargy and coma, large amounts can lead to death [2]. FA is easy to react with nucleophilic material, causing DNA damage [3]. Studies have shown that parts of the Alzheimer's disease are also associated with the intake of FA [4]. As a serious threat to human health, FA ranked second on the priority control list of toxic chemicals in China [5]. In 2004, FA was categorized in Group I as "carcinogenic to humans" by the International Agency for Research on Cancer (IARC) [6]. The United States Environmental Protection Agency recommended daily intake of FA as no more than $0.2 \mathrm{mg} / \mathrm{kg}$ of the body weight while WHO set it as $0.15 \mathrm{mg} / \mathrm{kg}$ of the body weight. In 1985, Italian health departments set limit of FA in cod and shellfish aquatic products respectively $60 \mathrm{mg} / \mathrm{kg}$ and $10 \mathrm{mg} / \mathrm{kg}$ [7], while Chinese ministry of agriculture, set it to $10 \mathrm{mg} / \mathrm{kg}$ in aquatic products since 2002 [8]. There are two ways resulting in high levels of FA, one is the artificial added, the other one is that aquatic products produce FA during frozen storage or processing. The endogenous FA is the main source of FA in aquatic products.

\section{The Background Concentration of Endogenous FA in Aquatic Products}

In the 1960s, when scholars started to study the formation of FA in marine fish and crustacean shellfish, they detected endogenous FA in the course of freeze storage and processing of the fresh marine fish without subjected to artificial factor. Studies showed that trimethylamine (TMA), dimethylamine (DMA) and FA concentrated in the freezing process of some aquatic products such as the squid [9] [10]. F. Bianchi et al. researched

\footnotetext{
*Corresponding author.
}

How to cite this paper: Zhang, X., Hui, Y.H., Cai, Y.Q. and Huang, D.M. (2015) The Research Progress of Endogenous Formaldehyde in Aquatic Products. World Journal of Engineering and Technology, 3, 272-276.

http://dx.doi.org/10.4236/wjet.2015.33C040 
levels of FA in 12 species (sea-fish, freshwater-fish and crustaceans), the results showed that FA content was variable, fishes belonging to the Gadidae family were the samples with the highest FA concentration [11]. Duan et al. successively determined the background value of FA in 699 fresh aquatic samples of 37 species which included 19 kinds of marine fishes, 9 kinds of crustaceans, 5 kinds of shellfish and 4 kinds of cephalopods. All samples revealed various levels of FA, especially the bummalo, gadus, loligochinensis, portunid had higher background values of FA. FA content in aquatic products was significantly different, the FA content of marine fishes was the highest, the cephalopods was higher, the crustaceans and shellfish was the lowest [12]. Yeh et al. compared the FA content in squid with the results from previous studies, the concentration of FA in squid was from 0.26 - $19.7 \mathrm{mg} / \mathrm{kg}$ [24].

\section{Generation Mechanism of Endogenous FA in Aquatic Products}

In recent years, both domestic and foreign scholars have suggested that animals could produce FA itself, as a kind of animal metabolites in the body, it had vital significance for some amino acid biosynthesis. According to the existing research results, it is generally believed that FA in aquatic products is produced by enzymatic pathway and thermal processing. Trimethylamine oxide (TMAO) widely exists in aquatic products, TMAO could resolve into DMA, TMA and FA under enzymolysis condition of trimethylaminek-N-oxide (TMAOase) [13]. Besides the enzymatic pathway, FA is steadily accumulated during the thermal processing [14] [15].

TMAO resolves under the action of bacteria (alteromonastetrodonis, putrefaciens) in fresh marine fish, but bacterial action is suppressed in frozen state. As aquatic products are usually stored in frozen state, the low temperature inhibits the growth of microorganisms in the process of storage, thus the effect of microorganisms to FA is small, the enzyme becomes the main influencing factor, and TMAOase is one of the main enzymes. TMAOase activity is present in a number of marine fishes. It is widely different between species, and even in the same fish, enzyme levels are different in organs and tissues. The TMAOase activity in white muscle is more than red muscle. TMAOase has particularly high level in cod, certain content in sepiidae and shellfish, barely level in freshwater fish. It is present higher in visceral organs (kidney, spleen, liver and pyloric caecum) than in tissue. M. Rey-Mansilla studied influence of biological condition and season on TMAOase activity. They found a correlation between TMAOase activity of kidney and season : during winter and spring (February to May), the months matching the spawning peak, high activities were detected, while in summer months the activity level was lower [16].

In addition, as early as 1979, Spinelli has found that the FA was produced by some non-enzyme pathway, especially by the high temperature heating [17]. Lin et al. reported that FA, TMA and DMA contents were very high in five different types of dried squid, $90 \%$ of the TMAO was converted to DMA and TMA after heating at $200^{\circ} \mathrm{C}$ for $1 \mathrm{~h}$ [18]. Zhu et al. investigated the effects of various thermal processing and various chemical substances on the conversion of TMAO to FA and DMA in squid. The result showed that high temperature processing promoted the conversion of TMAO to FA, and FA content increased with the temperature. A pH of about 6 - 7 accelerated the degradation of TMAO to FA, as well as $\mathrm{Fe}^{2+}$ alone or $\mathrm{Fe}^{2+}$ combined with cysteine and ascorbate promoted the formation of FA [19]. Spinelli et al. reported the Cys with $\mathrm{Fe}^{2+}$ or hemoglobin could also catalyze decomposition of TMAO to FA and DMA [20]. Ferris et al. proved the free radical was involved in the decomposition reaction by butadiene rounded up experiments [21]. Scholars used electron spin resonance (ESR) [22] evaluated different additives (tea polyphenols, calcium chloride, citricacid, trisodium citrate and resveratrol) on the decomposition of TMAO to FA by observing free radical signals, the result suggested that those additives decreased the concentration of FA, and scavenged the free radicals in the squid extract.

\section{Detection Methods}

Iben Ellegaad reported that FA present three states in aquatic products according to different combinations of FA with protein: one is free state, the other one is free and reversibly bound state which is available only through steam distillation under the sulfuric acid or phosphoric acid solution (1\% - 40\%), the third one is irreversible combined state [23].

Detection methods of FA include spectrophotometry, chromatography, fluorescence method, colorimetry and electrochemical method. These determination methods have their own advantages and disadvantages, generally spectrophotometry and chromatography are used more. Spectrophotometric method includes acetyl acetone me- 
thod, phloroglucinol method, phenylhydrazine hydrochloride method, chromotropic acid method, magenta-sulphurous acid method, chromatography can be divided into gas chromatograph (GC) or gas chromatography mass spectrometer (GC-MS), high performance liquid chromatography (HPLC), ion chromatography (IC), thinlayer chromatography (TLC), etc.

Principle of spectrophotometry is to make FA react with a compound, and then detect the reaction product with a color under the specific wavelength; acetyl acetone method is the most common method in spectrophotometry. People constantly improve spectrophotometric method, through the combination of advanced technology, improve its accuracy, sensitivity, make it more convenient, fast, safe, and practical [24] [25]. Such as Rozidaini used natural compound (onion juice), as a novel environmental-friendly chromogenic agent to detect the concentration of FA in aquatic products. The optimum response was obtained by heating the onion juice at $60^{\circ} \mathrm{C}$, $\mathrm{pH} 4.9$, reaction temperature of $103^{\circ} \mathrm{C}$ and reaction time of $17 \mathrm{~min}$. The method has a linear range of 0.5 to 15 $\mathrm{mg} / \mathrm{L}$ at $514 \mathrm{~nm}$ wavelength. This study demonstrates the potential application of onion juice as a simple, safe and environmental-friendly technique for determination of FA [26].

Principle of chromatography is to analysis the reaction product of derivatization reagent and FA by GC or HPLC, which are extracted by organic solvent. F. Bianchie valuated FA in fish products using a solid phase microextraction (SPME)-GC-MS method based on fiber derivatization with pentafluorobenzyl-hydroxyl-amine hydrochloride. Limit of detection (LOD) and limit of quantitation (LOQ) were calculated respectively with values of 17 and $28 \mu \mathrm{g} / \mathrm{kg}$. This method had good efficiency recovery of $94.8 \% \pm 1.7 \%(\mathrm{n}=3)$, and CV\% values of repeatability and between-day precision were lower than 3.2\% and 9.7\% [11].Ma et al. determined trace volatile FA in aquatic products by $\mathrm{aMoO}_{3} /$ polypyrrole intercalative sampling adsorbent with thermal desorption GC-MS. FA concentration in aquatic products could be quantified from $0.43 \mathrm{mg} / \mathrm{kg}$ to $6.6 \mathrm{mg} / \mathrm{kg}$ in all four aquatic products including fresh squid, fresh shrimp, dry squid, and dry shrimp. A good linear range was found in a concentration range from 0.02 to $20.35 \mu \mathrm{g} / \mathrm{L}$. The detection limit was achieved as $0.004 \mu \mathrm{g} / \mathrm{L}$ by this method. Good recoveries for spiked aquatic products were achieved in range of $75.0 \%-108 \%$ with relative standard deviations of $1.2 \%-9.0 \%$ [27].

Li et al. developed a HPLC method in order to investigate content of FA in squid and squid products. Based on steam distillation and 2,4-dinitrophenylhydrazine (DNPH) derivatization, formaldehyde was analysis by HPLC using ODS-C18 column at UV detector $(355 \mathrm{~nm})$. Detection limit was $8.92 \mu \mathrm{g} / \mathrm{L}$ in standard solution and $0.18 \mathrm{mg} / \mathrm{kg}$ in sample, and recovery was $83.09 \%-103.20 \%$ [28]. Chen et al. adopted HPLC method to detect FA based on microwave-assisted extraction (MAE) coupled online with derivatization, restricted access material (RAM) cleanup. Only small molecules are able to penetrate into the pores of RAM and interact with a stationary phase bonded on their innersurface, while large molecules are eluted with the washing solvent. The LOD was $0.27 \mathrm{mg} / \mathrm{kg}$. The intraday and interday precisions expressed as RSDs were $3.5 \%$ and $5.0 \%$, respectively. The recoveries obtained by analyzing 11 spiked aquatic products were in the range of $70.0 \%-105.0 \%$. Online MAE and RAM techniques were demonstrated to be rapid with little consumption of samples and reagents [29].

\section{Research Prospect}

Although there were many results of endogenous FA in domestic and abroad, some basic and key issues need further research and breakthrough. Firstly, more studies of background FA content in aquatic products should be added, because the recent study is scattered and dispersed, not considering the influence of storage time and temperature. Because of lack of a scientific and reasonable evaluation system of background content in endogenous FA, it does not play a practical role in the monitoring of FA content. Secondly, the causes of endogenous FA in aquatic products are unclear, the respective role of the enzymatic pathway and the thermal processing in different aquatic products is ambiguous. People are paying more attention to the development of vitro simulation system in the thermal processing and few researches on thermal processing in organism. Thirdly, each detection method of FA cut both ways, spectrophotometry has some advantages of simple equipment, low cost and fast operation, and disadvantages of poor accuracy, worse sensitivity, and easily influenced by complex food matrix. Chromatography with high sensitivity, stable derivatives, strong existence against interference, high recovery rate, convenient and rapid operation is widely used for detecting FA in aquatic products, however, it demands higher on equipment, long time on derivatization, cumbersome process in extraction, which makes it hard to meet the market demand. Therefore to establish a simple, rapid and sensitive examination method of FA is timely and necessary. 


\section{Acknowledgements}

This study was supported by the research grant (No. 2015T08) supported by the East China Sea Fisheries Research Institute, Chinese Academy of Fishery Sciences.

\section{References}

[1] Liteplo, R.G. and Meek, M.E. (2003) Inhaled Formaldehyde: Exposure Estimation, Hazard Characterization, and Exposure-Response Analysis. Journal of Toxicology and Environmental Health, Part B: Critical Reviews, 6, 85-114. http://dx.doi.org/10.1080/10937400306480

[2] Zhao, X.Q. and Zhang, Z.Q. (2009) Microwave-Assisted On-Line Derivatization for Sensitive Flow Injection Fluorometric Determination of Formaldehyde in Some Foods. Talanta, 80, 242-245. http://dx.doi.org/10.1016/j.talanta.2009.06.066

[3] IARC (2004) Monographs on the Evaluation of Carcinogenic Risks to Humans. Vol. 88, International Agency for Research on Cancer, Lyon.

[4] Li, F.X., Lu, J., Xu, Y.J., Tong, Z.Q., Nie, C.L. and He, R.Q. (2008) Formaldehyde-Mediated Chronic Damage May Be Related to Sporadic Neurodegeneration. Progress in Biochemistry and Biophysics, 35, 393-400. http://dx.doi.org/10.3321/j.issn:1000-3282.2008.04.006

[5] Tang, X.J., Bai, Y., Duong, A., et al. (2009) Formaldehyde in China: Production, Consumption, Exposure Levels, and Health Effects. Environment International, 35, 1210-1224.http://dx.doi.org/10.1016/j.envint.2009.06.002

[6] Noda, T., Takahashi, A., Kondo, N., et al. (2011) Repair Pathways Independent of the Fanconi Anemia Nuclear Core Complex Play a Predominant Role in Mitigating Formaldehyde-Induced DNA Damage. Biochemical and Biophysical Research Communication, 404, 206-210. http://dx.doi.org/10.1016/j.bbrc.2010.11.094

[7] MINSAN-Telegram No. 703/3266/6/1377 08.11.1985.

[8] China’s Ministry of Agriculture. Agricultural Industry Criteria, NY5172-2002.

[9] Phillippy, B.Q. and Hultin, H.O. (1993) Distribution and Some Characteristics of Trimethylamine-N-Oxide (TMAO) Demethylase Activity of Red Hake Muscle. Journal of Food Biochemistry, 17, 235-250. http://dx.doi.org/10.1111/j.1745-4514.1993.tb00470.x

[10] Kimura, M., Seki, N. and Kimura, I. (2000) Occurrence and Some Properties of Trimethylamine-N-Oxide Demethylase in Myofibrillar Fraction from Walleye Pollack Muscle. Fisheries Science, 66, 725-729. http://dx.doi.org/10.1046/j.1444-2906.2000.00118.x

[11] Bianchi, F., Careri, M., Musci, M. and Mangia, A. (2007) Fish and Food Safety: Determination of Formaldehyde in 12 Fish Species by SPME Extraction and GC-MS Analysis. Food Chemistry, 100, 1049-1053 http://dx.doi.org/10.1016/j.foodchem.2005.09.089

[12] Duan, W.J., Zhou, D.Q. and Zhang, R.L. (2011) Investigation of Background Concentration of Formaldehyde in Fresh Fishery Products. Chinese Agricultural Science Bulletin, 27, 383-390.

[13] Soottawat, B., Wonnop, V. and Munehiko, T. (2003) Partial Purification and Characterization of Trimethylamine-NOxide Demethylase from Lizardfish Kidney. Comparative Biochemistry and Physiology Part B Biochemistry and Molecular Biology, 135, 359-371. http://dx.doi.org/10.1016/S1096-4959(03)00082-4

[14] Li, J.R. and Zhu, J.L. (2006) Study on Control of the Formaldehyde-Producing in the Process Techniques of Dosidicus gigas Dried Squid Thread. Chinese Institute of Chemical Engineers, 6, 200-203. http://dx.doi.org/10.3969/j.issn.1009-7848.2006.01.042

[15] Fu, X.Y., Xue, C.H., Miao, B.C., et al. (2007) Effect of Processing Steps on the Physico-Chemical Properties of Driedseasoned Squid. Food Chemistry, 103, 287-294. http://dx.doi.org/10.1016/j.foodchem.2006.07.047

[16] Rey-Mansilla, M., Gonzalez Sotelo, C. and Perez-Martin, R.I. (2002) TMAOase Activity of European Hake (Merluccius merluccius) Organs: Influence of Biological Condition and Season. Food Science, 67, 3242-3251. http://dx.doi.org/10.1111/j.1365-2621.2002.tb09573.x

[17] Spinelli, J. and Koury, B.J. (1979) Nonenzymic Formation of Dimethylamine in Dried Fishery Products. Agricultural and Food Chemistry, 27, 1104-1108. http://dx.doi.org/10.1021/jf60225a036

[18] Lin, J.K. and Hurng, D.C. (1985) Thermal Conversion of Trimethylamine-N-Oxide to Trimethylamine and Dimethylamine in Squids. Food and Chemical Toxicology, 23, 579-583. http:/dx.doi.org/10.1016/0278-6915(85)90182-6

[19] Zhu, J.L., Li, J.R. and Jia, J. (2012) Effects of Thermal Processing and Various Substances on Formaldehyde and Dimethylamine Formation in Squid Dosidicus gigas. Science of Food and Agriculture, 92, 2436-2442. http://dx.doi.org/10.1002/jsfa.5649

[20] Spinelli, J. and Koury, B.J. (1981) Some New Observations on the Pathways of Formation of Dimethylamine in Fish 
Muscle and Liver. Agricultural and Food Chemistry, 29, 327-331.http://dx.doi.org/10.1021/jf00104a027

[21] Ferris, J.P., Gerwe, R.D. and Gapsi, G.R. (1967) Detoxication Mechanisms. II. The Iron-Catalyzed Dealkylation of Trimethylamine Oxide. American Chemical Society, 89, 5270-5275. http://dx.doi.org/10.1021/ja00996a033

[22] Zhu, J.L., Jia, J., Li, X.P., Dong, L.L. and Li, J.R. (2013) ESR Studies on the Thermal Decomposition of Trimethylamine Oxide to Formaldehyde and Dimethylamine in Jumbo Squid (Dosidicus gigas) Extract. Food Chemistry, 141, 3881-3888. http://dx.doi.org/10.1016/j.foodchem.2013.06.083

[23] Iben, E.B. (1996) Determination of Formaldehyde in Frozen Fish Formaldehyde Dehydrogenase Using a Flow Injection System with an Incorporated Gel-Filtration Chromatography Column. Analytica Chimica Acta, 320, 155-164. http://dx.doi.org/10.1016/0003-2670(95)00561-7

[24] Yeh, T.S., Lin, T., Chen, C.C., Wen, H.M. (2013) Analysis of Free and Bound Formaldehyde in Squid and Squid Products by Gas Chromatography-Mass Spectrometry. Food and Drug Analysis, 21, 190-197. http://dx.doi.org/10.1016/j.jfda.2013.05.010

[25] Zhu, Y., Peng, Z., Wang, M., Wang, R.R. and Rui, L.M. (2012) Optimization of Extraction Procedure for Formaldehyde Assay in Smoked Meat Products. Food Composition and Analysis, 28, 1-7. http://dx.doi.org/10.1016/j.jfca.2012.07.002

[26] Rozidaini, M.G. and Wan, A.A. (2014) Development of Formaldehyde Detection Method Using Onion Juice as Chromogenic Agent. Desalination and Water Treatment, 52, 1093-1100. http://dx.doi.org/10.1080/19443994.2013.826321

[27] Ma, Y.J., Zhao, C., Zhan, Y.S., Li, J.B., Zhang, Z.M. and Li, G.K. (2015) Separation and Analysis of Trace Volatile Formaldehyde in Aquatic Products by a MoO3/Polypyrrole Intercalative Sampling Adsorbent with Thermal Desorption Gas Chromatography and Mass Spectrometry. Separation Science, 38, 1388-1393. http://dx.doi.org/10.1002/jssc.201400951

[28] Li, J.R., Zhu, J.L. and Ye, L.F. (2007) Determination of Formaldehyde in Squid by High Performance Liquid Chromatography. Proceedings of the 4th Annual Conference of the east and west food top BBS of Chinese Institute of Food Science and Technology, Hangzhou, 11-13 November 2007, 127-130.

[29] Chen, L.G., Jin, H.Y., Xu, H.Y., et al. (2009) Microwave-Assisted Extraction Coupled Online with Derivatization, Restricted Access Material Cleanup, and High-Performance Liquid Chromatography for Determination of Formaldehyde in Aquatic Products. Agricultural and Food Chemistry, 57, 3989-3994. http://dx.doi.org/10.1021/jf900136x 